\title{
Responsibilities borne by a dental health professional towards public dental health education and awareness
}

\author{
Nafis Ahmad ${ }^{1 *}$, Zeba Jafri' ${ }^{2}$, Madhuri Sawai ${ }^{3}$, Nishat Sultan ${ }^{4}$ \\ ${ }^{1-4}$ Professor, Dept. of Prosthodontics, Faculty of Dentistry, Jamia Millia Islamia, New Delhi, India
}

*Corresponding Author: Nafis Ahmad

Email: khannafis08@gmail.com

\begin{abstract}
Dental public health is a unique and a challenging specialty, because the patient per se is just not a single entity but the whole community or a population, like a school, neighborhood, city, state, or the entire nation. At the community level the concept of dental health education has its importance as the oral health is essential for the overall health and wellbeing. With the ever increasing links between oral health and systemic health, it is a social and professional responsibility of a dental health professional to educate the community about oral health issues. Poor oral health affects the quality of day to day life both at psychological and social aspect.

This paper aims to present a few efforts that can be put forward, as a dental health professional, for bringing awareness, improving oral health literacy, empowering individual's ability to maintain their oral health and seek dental treatment in time and also to accept oral health importance as a priority.
\end{abstract}

Keywords: Public dental health, Oral health programme, National oral health survey, Lack of awareness, Dental education camps.

\section{Introduction}

Dental Public Health is defined as "The science and art of preventing oral disease, promoting oral health and improving quality of life through the organized efforts of society, organizations, public and private, communities and individuals". ${ }^{1}$ It has been observed that dental or oral health has mostly remained as an ignored and unrealized major social problem.

A National Oral Health Survey was conducted in 20022003 by Indian Dental Association which was published in $2004^{2}$ highlighted the state of oral health in India. According to the survey $95 \%$ of the population suffered from gum disease, over $80 \%$ under 15-year had caries, dental caries (tooth decay) was the most common chronic childhood disease and only $50 \%$ used a toothbrush and just $2 \%$ of the population visited the dentist.

The poor attitude of patient towards oral healthcare ${ }^{3}$ is also a big hurdle in seeking treatment.

Among the most shocking of revelations is that nearly half of the Indian population does not use tooth brush. ${ }^{2}$ Thirty per cent of the population 15 years or older $-47 \%$ men and $14 \%$ of women - either smoked or chewed tobacco, which translates to almost 195 million people. ${ }^{4}$ Tobacco-related cancers is the most prevalent of cancers. Annually 1, 30,000 people succumb to oral cancer; this translates into approx 14 deaths per hour in India. ${ }^{2}$ what could be the reasons to this poor state of oral health in India?? There can be many factors attributed to the poor attitude towards oral health in India: ${ }^{5}$

The low priority for oral health amongst patients (19\%);

Patients cannot afford treatments $(16 \%)$;

Low level of patient's education (15\%);

Common myths and misconceptions associated with routine procedures such as extraction and scaling (14\%);

Lack of routine oral habits i.e. brushing, flossing etc. $(10 \%)$.
Majority of people do not realize the importance of oral health. There is a growing body of evidence that indicates that oral health is directly linked to general health. It was stated in the first Surgeon General's Report on Oral Health in the United States "oral health and general health should not be interpreted as separate entities." Poor oral healths negatively affect growth, development, nutrition, communication, self-esteem, and various general health problems.

The Majority of the people are unaware about the relationship between oral hygiene and systemic diseases or disorders. To promote oral health care, the oral health literacy must improve. The public perceptions and attitudes towards oral health care requires a change and lack of awareness, needs to be addressed.

The task of spreading this awareness extends beyond clinics to general masses and can be achieved by various relevant public health awareness and outreach programs through various mediums, such as street plays, dental camps, mobile clinics, print/press media, electronic media e.g. radio talks and teleshops, Internet and social media, and other social activities. Although the responsibilities for health are borne by individuals, but still in part it is the social and professional responsibility of dental health professionals to educate the community about oral health issues, assisted by health care providers, educational institutions, researchers, employers, communities and policymakers at all levels of society.

This paper presents few efforts that can be put forward as a dental health professional that includes an array of community health program for population in and beyond clinical set-up for improving oral health literacy, bringing awareness, empowering individual's ability to maintain their oral health and seek dental treatment in time and also to accept oral health importance as a priority. 


\section{Materials and Methods}

Organization of oral health Camps for school children

Schools provide an important setting for promoting health, as they reach over 1 billion children worldwide and, through them, the school staff, families and the community as a whole. Health promoting messages can be reinforced throughout the most influential stages of children's lives, enabling them to develop lifelong sustainable attitudes and skills.

In many schools camps can be organized with an aim for the prevention of diseases, early diagnosis, treatment and follow up of diseases and awakening the health consciousness in children.

The children can be motivated and educated for proper oral hygiene care and proper eating habits. More importantly the children were sensitized to overcome the fear of visiting to dentists.

\section{Street plays / Nukkad nataks to be organized in public areas}

The idea of a street play is to propagate social messages in a humorous and sarcastic way and create awareness among the masses. A street play, or "nukkad natak", is characterized by highly enthusiastic and energetic performance so as to attract maximum crowd. On occasion of Anti tobacco day, Dentist's day, oral health day and Swatch Bharat mission or on any other day various street plays may be organized in public areas in an effort to bring out awareness.

Tele communications: Radio talks and Television shows Television shows and Radio talk delivered on radios will help the public to interact and find answer to their queries. Myths related to dental treatment is a big hindrance among society for visiting and taking treatment in time. These talk shows have especially helps out in spreading the awareness about the facts behind these myths associated with oral health treatment to masses.

\section{Oral health Camps via mobile dental clinic to different remote places}

Oral health camps can be organized with a functionally equipped mobile dental clinic for giving basic and free treatment to poor people. During the procedures they should be instilled to realize the importance of oral health and motivated to take treatment in time.

\section{Through social media/ internet}

Although it reaches out to people mainly with better socioeconomic strata which are considered to have better oral hygiene status but more prone to systemic diseases like diabetes and cardiovascular diseases which is much related with oral health. Diabetes has been considered as the two way street for periodontal diseases where presence of one worsens the condition of other. Social media and internet are used a lot these days and could be a good medium to aware people of their oral health care.
Spreading dental awareness by one to one contact in and out of professional setup

This method as such does not need much effort but a little time to communicate with people on the importance of their oral health. Every dental health professional must feel the responsibility of not just providing the dental treatment but also imparting information on oral health including its impact on general health within their professional setting. They should seek opportunities to raise the profile of oral health within their own social environment in day to day life as well.

\section{Conclusion}

All these methods of reaching and educating the public will not only ensure a healthy individual but a healthy society as well. Furthermore focus on prevention, policies, programs and organized community efforts can maximize limited resources and help provide public to great unmet dental needs.

\section{Source of funding}

None.

\section{Conflict of interest}

None.

\section{References}

1. Andersen R, Marcus M, and Mashshigan M. A comparative system perspective on oral health promotion and disease prevention. In: Oral health promotion: Socio-dental sciences in Action. Munksgaard International Publishers, Copenhagen. 1995.

2. National Oral Health Survey. 2004. Conducted by Indian Dental Association under national oral health programme : Available from: http://nohp.org.in/aboutus/WakeUpCallAction.aspx

3. Pritma Singh. Dental health attitude in Indian society. J Int Soc Prev Community Dent 2013;3(2):81-4.

4. Rani M, Bonu S, Jha P, Nguyen SN, Jamjoum L. Tobacco use in India: Prevalence and predictors of smoking and chewing in a national cross sectional household survey. Tob Control 2003;12:e4.

5. Kakde S., Bedi R. and Verma M. Oral health inequalities: a call for action to improve oral health in India. Int Dent $J$ 2013;63:324-8.

6. Oral Health in America: A Report of the Surgeon General online available at: http://www.nidr.nih.gov/sgr/oralhealth.asp

How to cite this article: Ahmad N, Jafri Z, Sawai M, Sultan N. Responsibilities borne by a dental health professional towards public dental health education and awareness. Int J Oral Health Dent 2019;5(3):166-7. 